\title{
الحماية المدنية للمستهلك في العقود الإلكترونية (دراسة هقارنة)
}

م. م. محمد جابر

كلية التربية / جامعة واسط فمد فيز

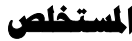

لقد قسمنا بحثنا الموسوم (الحماية المدنية للمستهلك في العقود الاكترونية ـ دراسة مقارنة) إلى مقدمة ومبحثين وخاتمة ـ اعتمدنا في

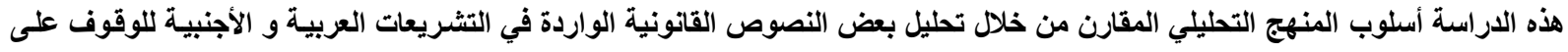

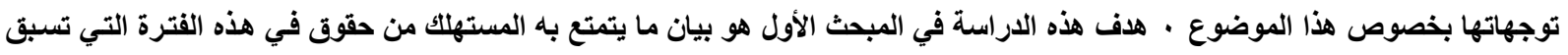

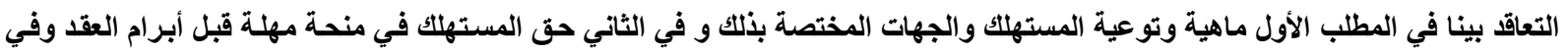

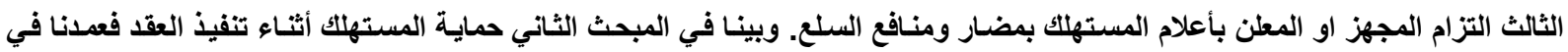

$$
\begin{aligned}
& \text { المطلب الأول الى حق المستهلك في العدول عن العقد وفي الثاني التزام المنتج أو المطن بضمان المطابقة } \\
& \text { الكلمات المفتاحية : العقد , القانون , حماية , المستهلك , الإكترونية }
\end{aligned}
$$

\section{Abstract}

We have divided our thesis (civil protecation of consumers in electronic contracts -comparative study) into an introducation and two chapters and conclusion .

We have adapted, in this study, the method of comparative analysis by analyzing several legal texts that are found in Arab and foreign legislation in order to know their orientations concerning this subject.

The aim of this study, in the first chapter, is to clariy what rights do the consumer has in the period before doing the contract while, in the first position; who and what kindis the consumer and what are the competent authorities of that, in the second position is the right of giving him a grant of time limit before doing the contract, and in the third position is the commitment of the supplier or advertiser of telling the consumer of the advantages and disadvantages of the commodity.

However, in the second chapter is the way of protecting the consumer during doing the contract being discussed In the first point, we discussed the consumers right of abandon the contract and in the second is the commitment of the seller of ensure of compliance

Key Words : Contract ,Law , Protection , Consumer , Eletronic .

إنّ التطور التقني في مجال الاتصالات والتواصل بين الأشخاص في مختلف ارجاء العالم قد أدّى إلى

ظهور نوع جديد من التجارة ألا وهي التجارة الإلكترونيـة التي تتم بين غائبين, إضـافة الى ذلك يشـهـ العـالم

اليوم تقدما واضحا وملموسا في مجـال الصناعات الاستهلاكية و إزدادت تبعـا لذلك رغبـة الفرد في التزود و ون

الاستفادة من تلك الصناعات في مجال حياته اليومية , ولكن لا يخفى على الجميع إنّ المنتج يحاول تحقيق أكبر

قدر من المكاسب حتى ولو كان على حساب إنتاج سلع رديئة تضرّ بالمستهللك , ويعتبر من أهم المشـاكل التي

تواجه التجارة الإلكترونيـة هو حمايـة المستهلك حيث تشير الإحصـاءات الى تزايد عدد المستهلكين الكترونيا

و إنّ أغلب المستهلكين يفتقدون إلى الخبرة والدراية في مجال السـع الاستهلاكية روكذلك صعوبة التحقق من

صلاحية السلعة لأداء الغرض المقصسود لكون هذا النوع من البيوع يتمّ عن طريق واقع افتر اضـي لا تسمح

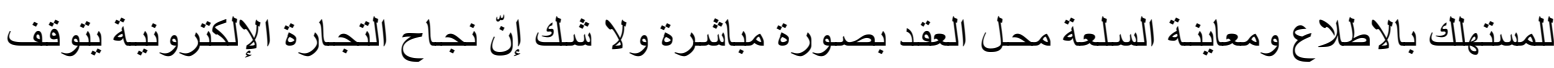

على مدى الحماية التي يتمتع بها المستهلك فكلما كان الفرد يشـعر بوجود قو اعد قانونيه تحمي إرادته في هذا 
النوع من البيوع كلما إزداد إقدام الأفراد على هذه البيوع •أما بصدد تعريف المستهللك فنجد إنّ المسادة الأولى

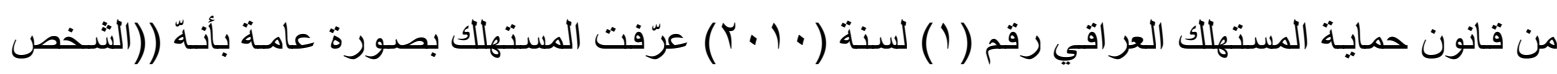
الطبيعي أو المعنوي الذي يتزود بسلعة أو خدمـة بقصد الإفادة منها )) أمـا المستهلك في العقود الإكترونية بشكل خاص فيمكن تعريفه ((كل شخص يتزود بسلعة أو خدمة بقصد الإفادة منها عن طريق وسائل الاتصال)) لذا فإنّ المستهلك في عقود التجارة الإلكترونية هو الثخص الذي يتعاقد على شر اء السلعة بوسـائل الاتصـال كالأنترنيت أو الهاتف.

و لأجل التوصل الى نتائج دقيقه من هذا البحث لذا آثرنا أنّ تكون اسلوب دراسة هذا البحث مقارنـة بين

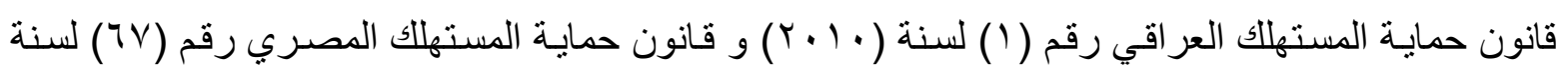

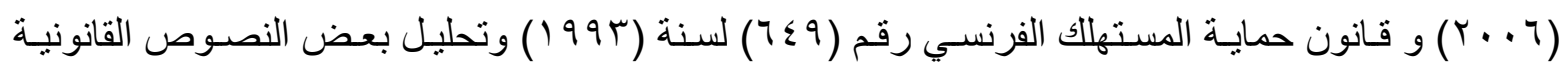
الو اردة بحماية المستهلك العر اقي مع الإشارة لبعض القوانين الخاصة بحماية المستهلك •و عليه سيتم تقسيم هذا البحث الى مبحثين يسبقهما مقدمة نتتاول في المبحث الأول منه حماية المستهلك عند التعبير عن إرادته مقسمه على ثلاثة مطالب نتناول في الأول منه توعية المستهلك وفي الثاني منح المستهلك فرصـة للتفكير وفي الثالث الالتزز ام بـإعلام المستهلك أمـا المبحث الثاني فسنبين فيـه حمايـة المستهلك عند تتفيذ العقد مقسم على مطلبين نتناول في الأول منه حق المستهلك في العدول عن العقد وفي الثاني منـه الالتز ام بضمان مطابقة المبيع وفي

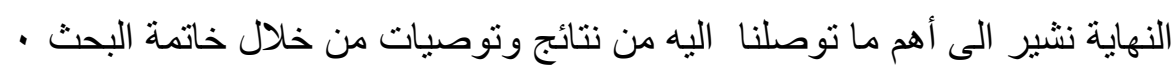

\section{المبحث الأول- حماية المستهلك عند التعبير عن إرادته}

لا تقتصر الحماية التي أقرتها التشريعات المدنية أثتاء تتفيذ العقد فقط بل تمتد هذه الحمايـة الى الفترة

التي تسبق إبر ام العقد وتسمى بالفترة السابقة على التعاقد لكون أغلب المستهلكين لا يتمتعون بـالخبرة و الدرايـة وتحاول الثركات المنتجة إغراءهم ودفعهم على التعاقد •ولقد توصل الفقه الى عدة وسـائل تؤدي الى حمايـة المستهلك وإحاطته بالمعلومات الكاملة قبل إبر ام العقد لذا سنقسم هذا المبحث إلى ثناثة مطالب نتناول في الأول منهـا تو عيـة المستتهلك ونتنـاول في الثناني منحح المستنهلك مهلـة للتفكير ونتنـاول في الثالث الالتز ام بـإعلام المستهل:ك:

\section{الامطاب الأول- توعية المستهدلك}

لقد سعى الققه والقضاء الى حماية المستهلك ليس بفرض التزامات على عاتق المنتج أو البائع فحسب بل إستعان بأساليب التوعية الحديثة من أجل إحاطة المستهللك بمعلومات المنتجات ومـا يحبط بها من مخـاطر و الهدف من ذلك هو حماية الشريحة الأكثر إنتشارا في المجتمع ألا و هي شريحة المستهلكين ،ويختلف توعية

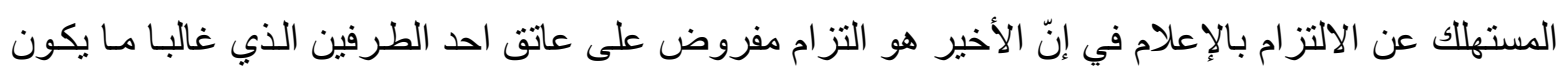

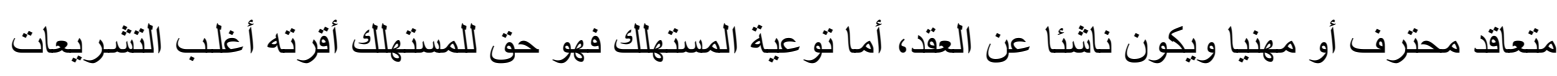
وتمارسه جهات مختصة لغرض تبصير المستهلك بمضار وفو ائد السلع ، ولغرض بيان مضمون هذا الالتزام 
و أساليبه سنقسم هذا المطلب الى فر عين نتخاول في الأول منـه مضمون توعيـة المستهلاك وفي الثاني الجهات : المختصة بتو عية المستهلك فئك

\section{الفرع الأول- هضمهون توعية المستهـك}

لا شكّّ إنّ درجات المعرفة متفاوتـة بين النـاس حول الإحاطـة بالمعلومـات الخاصـة بالسـلع الإستهلاكية و أغلب المستهلكين يكونون قليلي الخبرة والدراية بمواصفات هذه السلع ،و هذا يخالف الطرف الآخر في العقد

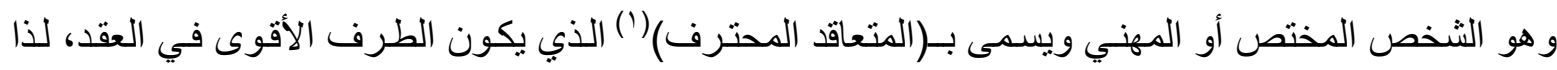
يجب رفع مستوى الوعي الإستهلاكي لدى الطرف الضعيف وهو المستهلك لغرض تحقيق التوازن بين طرفي العلاقـة العقديـة لا سـيما و إنّ هدف غالبيـة التشـريعات هـو حمايـة المسـتهلك , وتختلف وسـائل نشـر الـوعي الاستهلاكي بين المستهلكين , حيث يذهب البعض(؟) الى إنـة يجب تتشيط دور الإعلام بكل وسـائله المرئية

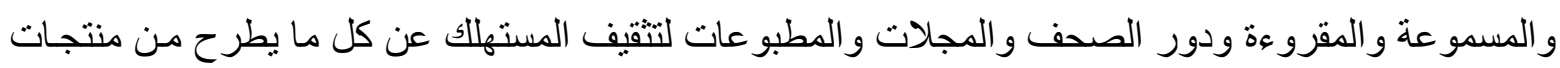
في الأسو اق وبيان أيجابياته وسلبياته وتعريف المستهلك بكل حقوقه و التزاماتـه وتوجيهه بشكل مستمر رحيث نلاحظ قصور الأعلام في نشر الثقافة الاستهلاكية مما أدى الى جهل المستهلكين بحقوقهم وهو ما جاء به قانون

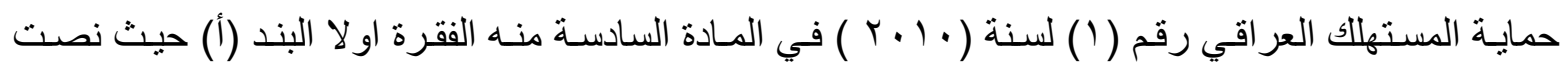
((للمستهلك الحق في الحصول على جميع المعلومات المتعلقة بحماية حقوقه ومصالحه المشروعة)( وكذللك مـا

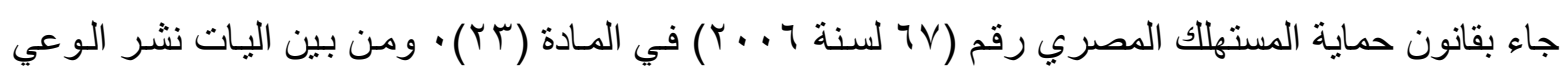
الاستهلاكي هو ترسيخ الوعي والثقافة فيما يخص ممارسة المستهلك لحقه في اختيار الأنسب و الأفضل للخدمة المتاحة وفقا لرغبته و الحصول على الخدمات التي تعقب عملية البيع كضمان الصيانة وضمان عدم العطل فيما يخص بعض الأجهزة وفقا للعقد المبرم مع الطرف الآخر (َ) ويجب التوعية بأبعاد المستهـلك عن الإعلان

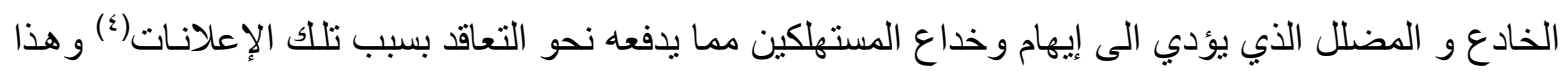
ما أكده قانون حماية المستهلك العر اقي في مادته السابعة الفقرة الخامسـة التي نصـت على (عدم الترويج بأيـة وسيلة من وسائل الإعلام والنشر و الدعاية للسلعة او الخدمة التي لا تتوفر فيها المواصفات القياسبة المحلية أو

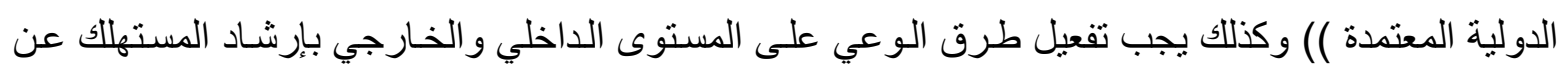

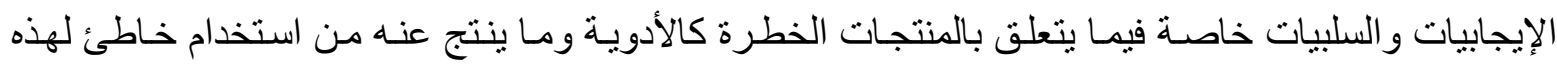
السلع ويسميه بعض الفقه(0) (بحق المعرفة) الذي يؤدي الى تنوير المستهلك الإلكتروني بكل المعلومـات التي

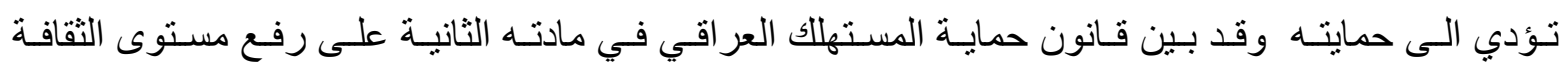

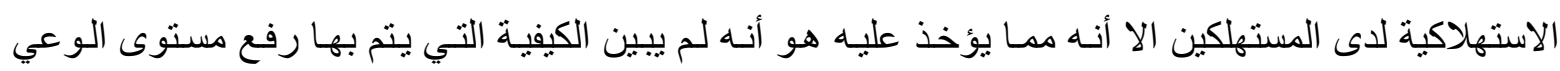

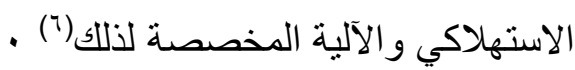

\section{الفرع الثاني- البهات المختصة بتوعية المستهلك}

لم تكتف التشريعات الوضعية ببيان آليات و وسائل نشر الوعي الاستهلاكي ولكن اهتمت أيضـا بييان الجهات المختصة بتوعية المستهلك ومن هذه الجهات التي كانت الأولى في الظهور هي الجمعيات التعاونية 
الاستهلاكية)(V) وتنشـأ هذه الجمعيـات بنـاءاً على رغبـة المستهلكين أنفسـهم وتهنت ببيـان مضـار ومنـافع السـع

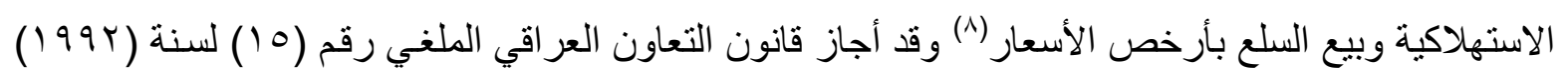

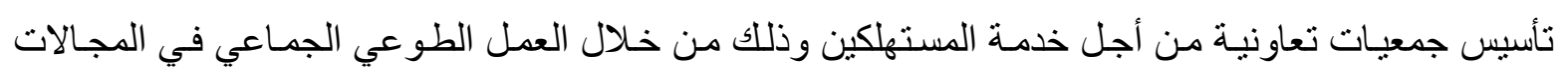

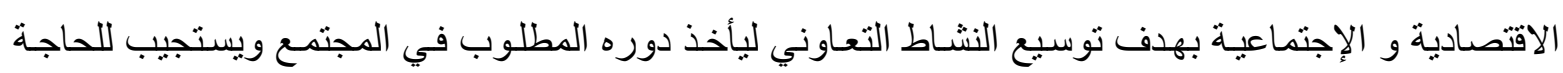
الملحة للمستهلكين في التزود بالسلع الإستهلاكية التي تلبي رغباتهم وقد أدى ظهور هذه الجمعيات الى خلق الوعي الإستهلاكي لاى المستهلك حول السلع و الخدمات و علاقتها بصحة المستهلك من خلال طبع دوريات من

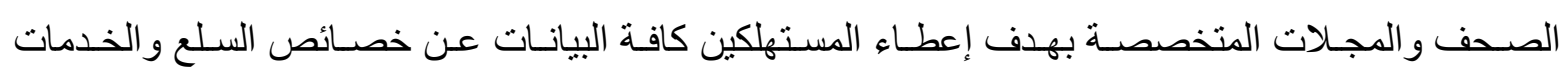
المعروضة في الأسواق(9) ولكن دور هذه الجمعيات بدأ يضمحل في الوقت الحاضر نظرا للتطور الإفتصسادي الكبير وزيـادة وسـائل نشـر الـوعي الإستهلاكي بسـبب ظهور التقنيـات الحديثـة في التواصـل وعدم اهتمـام الحكومات بها , وقد أعقب ظهور هذه الجمعيات إنشـاء جهات متخصصـة بحمايـة المستهلك تهدف الى نشر الوعي الإستهلاكي وتوعية المستهلك الى مضـار ومنـافع السـلع ومن هذه الجهات مـا أشـار إليهه قانون حمايـة

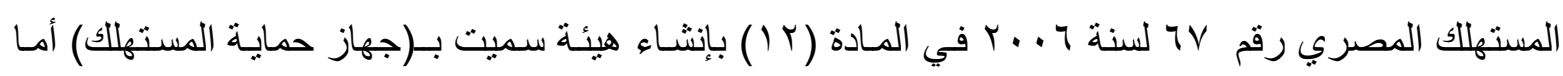

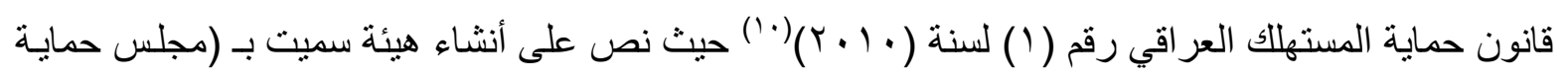

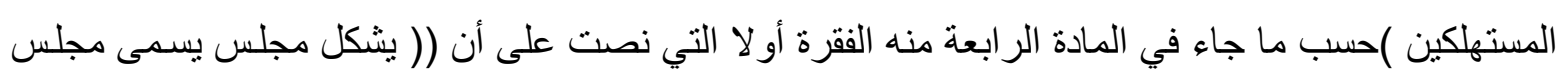
حماية المستهلك يتمتع بالثخصية المعنوية و الاستقلال المالي و الإداري يرتبط بمجلس الوزراء)) ويتألف من عدد من الأعضاء يمثلون عدة وزارات وقطاعات مختلفة ويتولى اختصاصات مختلفة منها رفع مستوى الوعي بلون الإستهلاكي وتلقي الثكاوى و التحقيق فيهاو إتخاذ الإجر اءات والقرارات و التوصيات المختلفة بشـأنها وأشـار

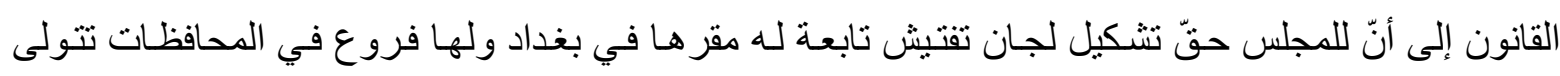

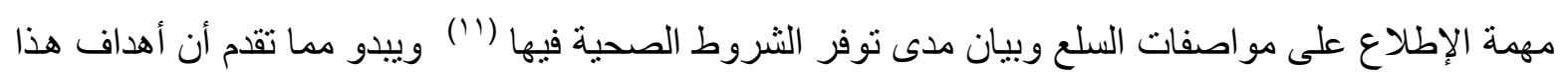

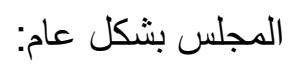

ا - إرشاد المستهكين الى سبل التأكد من ملائمة السلع الاستهلاكية لحاجتهم الثخصية r- خلق الوعي الإستهلاكي لدى المستهلك حول السلع و الخدمات و علاقتها بصحته r- إجر اء الاستطلاعات و الأبحاث و إعداد الدر اسـات المتخصصـة بالسلع و الخدمات التي تطرح

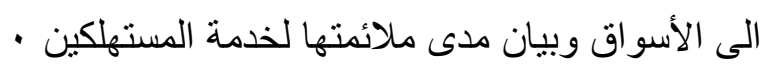

\section{الاطلب الثاني- هنح المستهلك ههلة للتفكير}

لا يتمتع المستهلك في عقود التجـارة الإلكترونيـة في أكثر الأحيـان بفرصـة كافيـة لمر اجعـة الثـروط

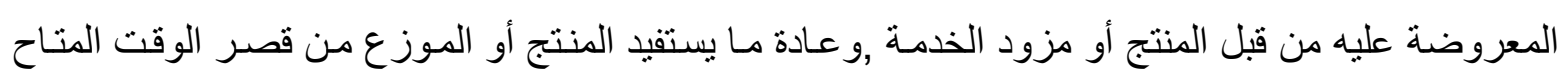
للنظر في الثروط المعروضة على الطرف الآخر ليحصل منه على التعاقد دون منحه فرصة لمر اجعة العقدو وله

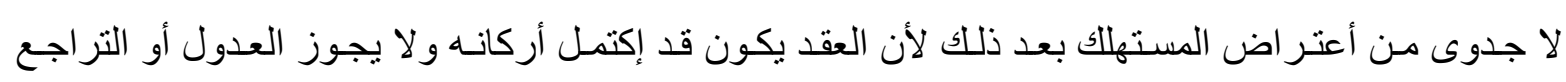

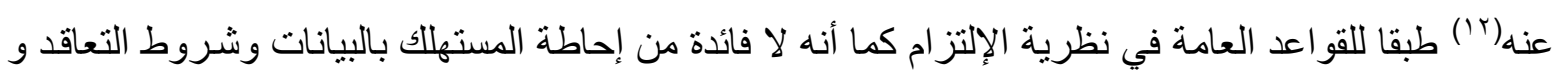


مو اصفات السلعة محل العقد دون منحهـ مهلة أو فرصة للتفكير قبل إبرام العقد ،وتبعا لذلك هنالك رأي في

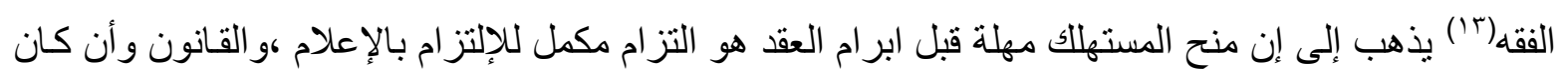

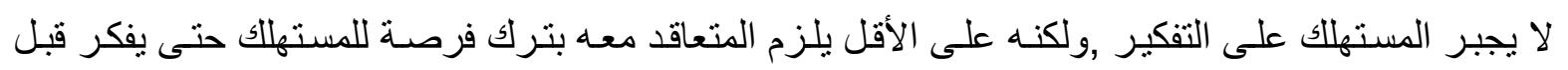

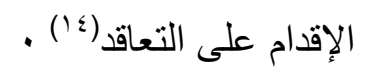

و الهاف من هذا الإلنزام للمتعاقد المحترف أو المهني قبل المستهلك هو القضاء على ظـاهرة شائعة

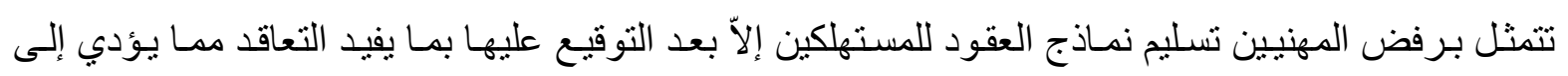

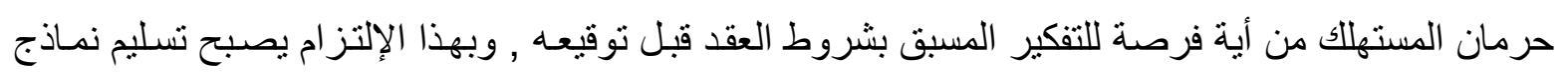

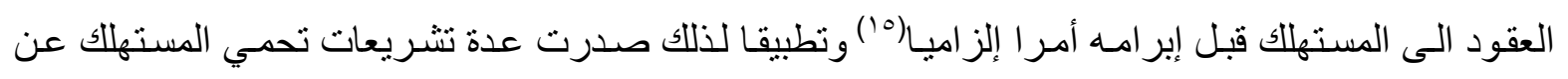

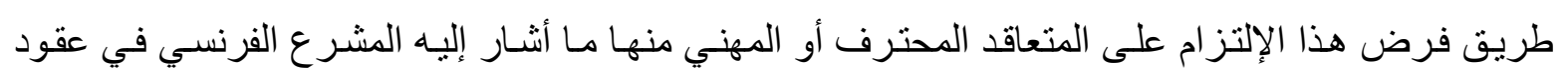

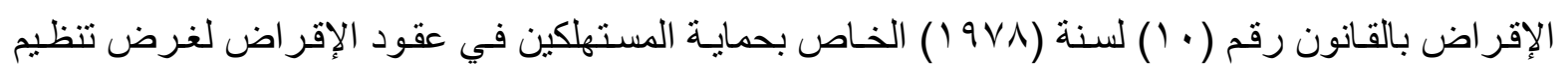

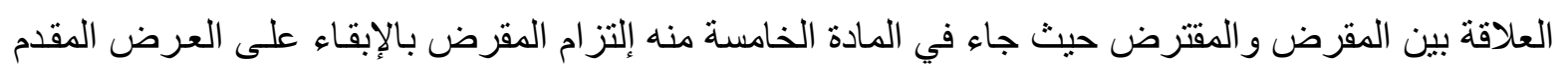

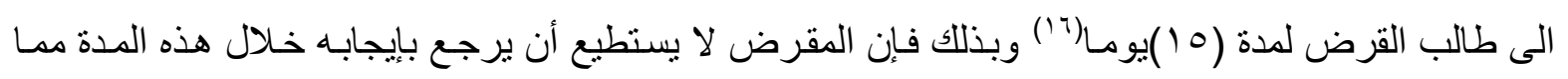

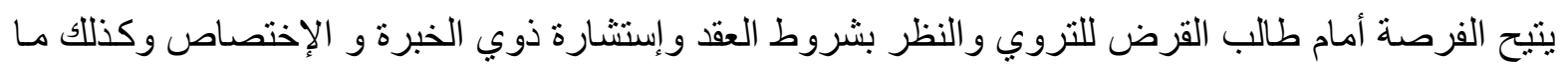

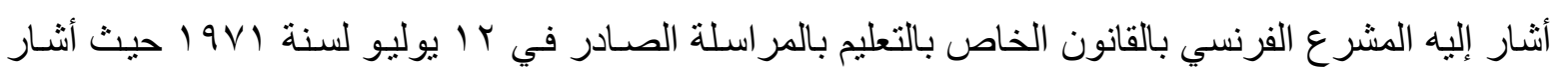

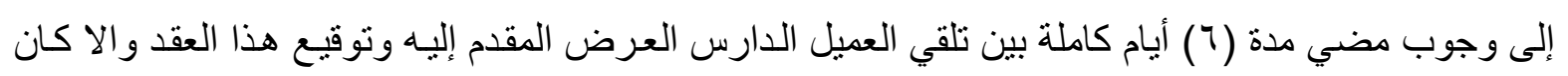

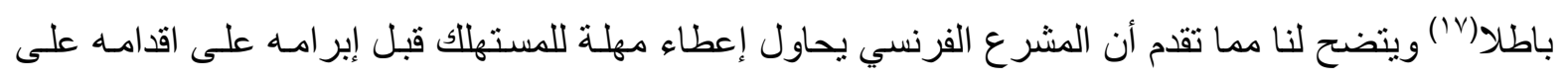

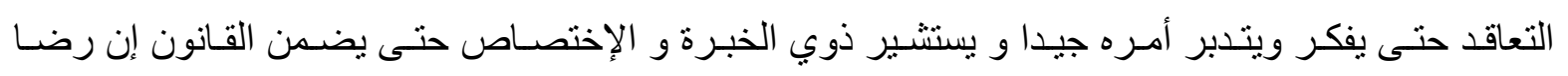

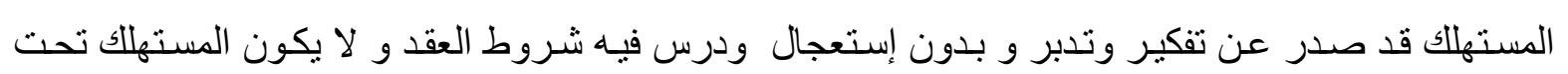

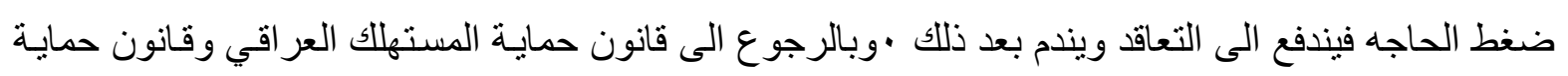

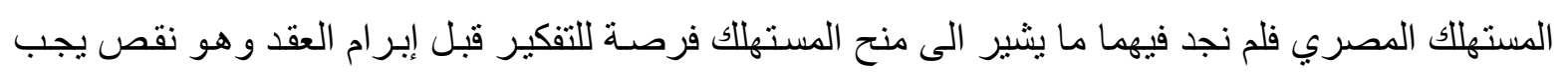

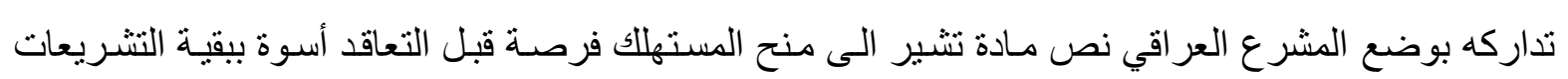

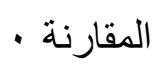

الامطب الثالث- الالترام بإعلام المستهلك

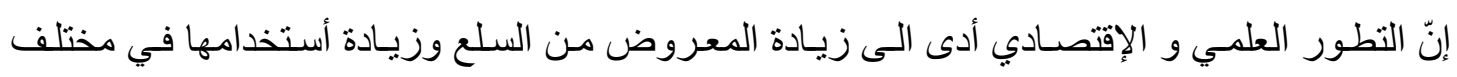

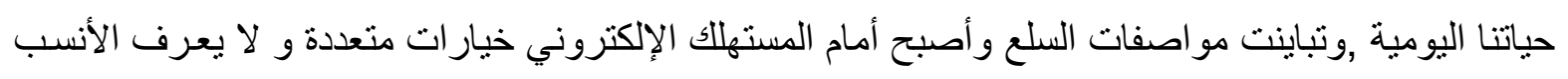

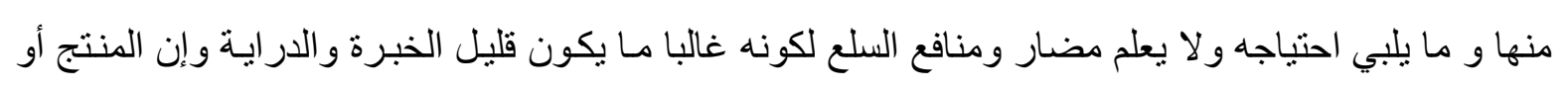

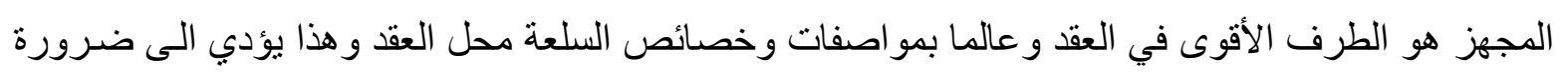

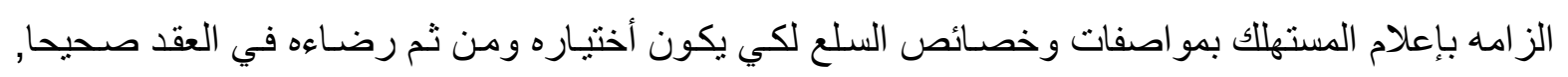

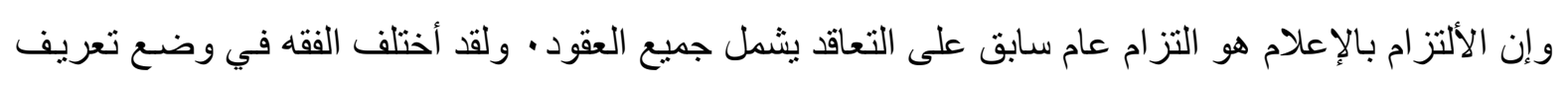
محدد له فعرفه البعض بأنه (( التزام سابق على التعاقد ينعلق بألتزام أحد المتعاقدين بأن يقدم للمتعاقد الآخر 
عند تكوين العقد جميع البيانات اللازمة لإيجاد رضا سليم ومتنور وعلى علم بكافة تفاصيل العقد وذلك بسبب طبيعة العقد أو صفة أحد طرفيه أو طبيعة محله أو أي اعتبار آخر يجعل من المستحيل على أحدهما أن يلم ببيانات معينه أو يحتم عليه منح ثقة مشرو عة للطرف الآخر الذي يلتزم بنـاء على هذه الاعتبار ات بـالالتزام

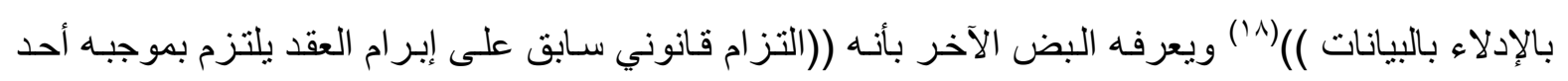

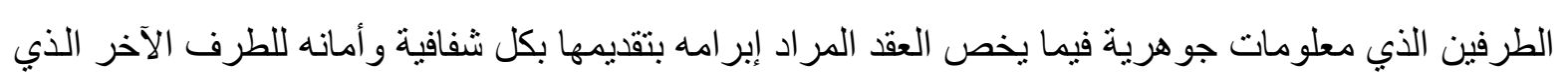

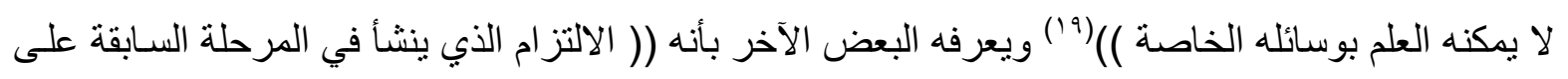

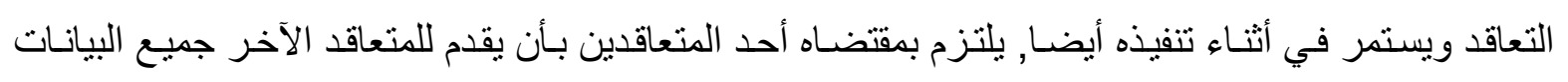
و المعلومات المتعلقة بالسلعة محل العقد بهدف تكوين رضا حر وسليم عند التعاقد وحصوله على أكبر فائدة من

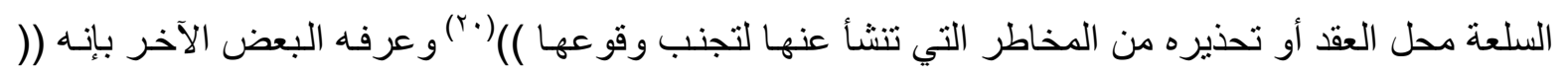
تنبيه أو إعلام طالب التعاقد بمعلومات من شـأنها القاء الضوء على واقعة معينة أو عنصر من عناصـر العقد

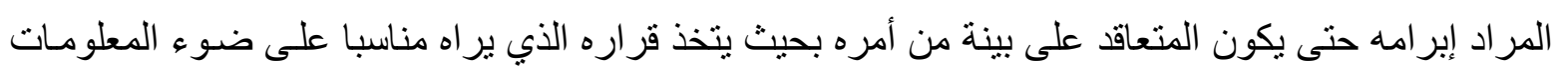

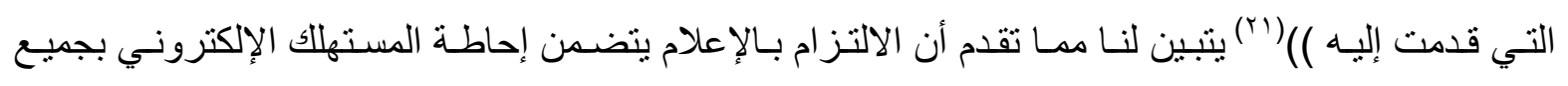

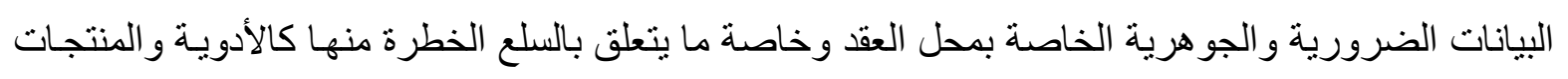

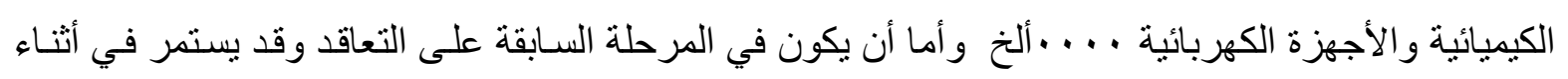
تنفيذه ايضا(r) وقد أختلف الفقه بصدد بيان الطبيعة القانونية لهذا الالتز ام فذهب البعض الى أنه التزام عقدي

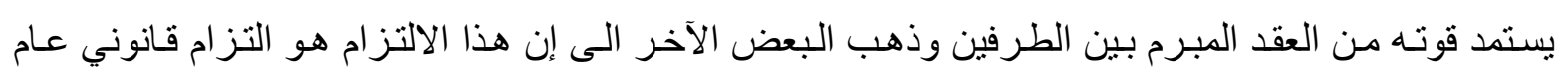

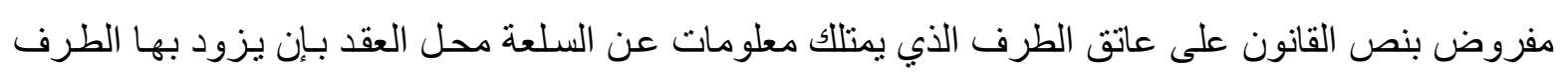

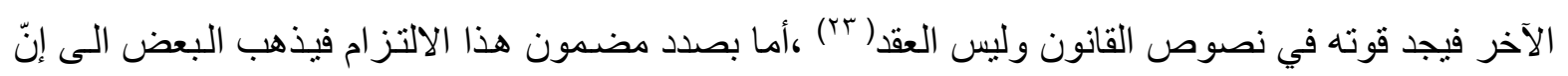
مضمون الالتز ام بالإعلام هو إحاطة المستهلك بمعلومات و افية حول المنتج وتتضمن وصف المنتج أو السلعة

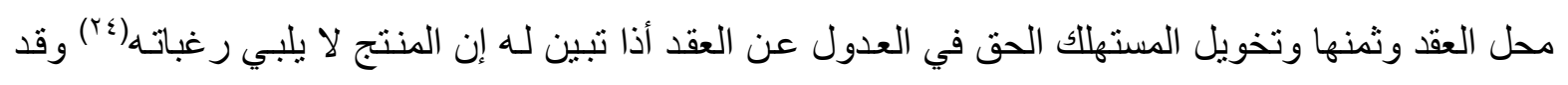
أنتارت بعض التشريعات الى حق المستهلك في أحاطته علما بجميع بيانـات المنتج ومن هذه التشريعات هو

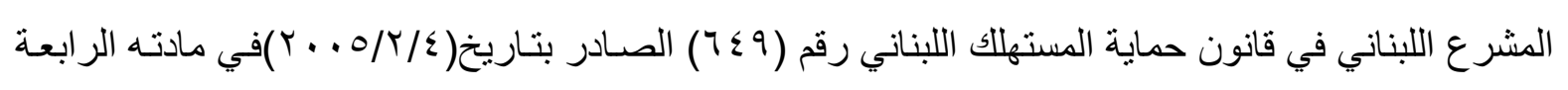

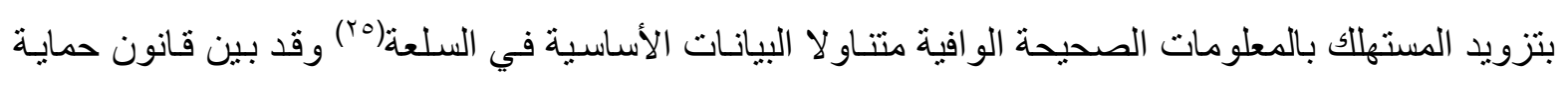

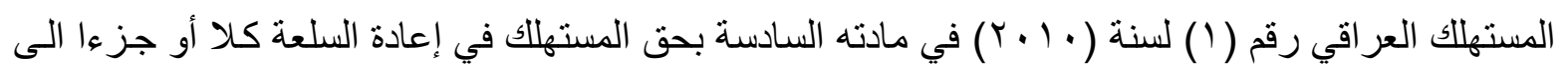

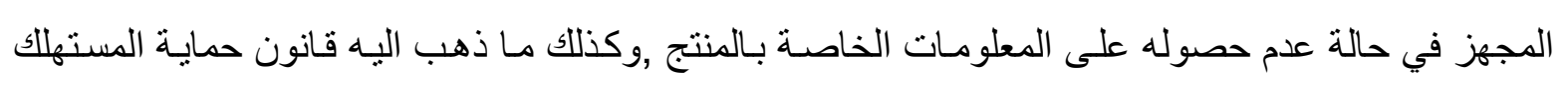

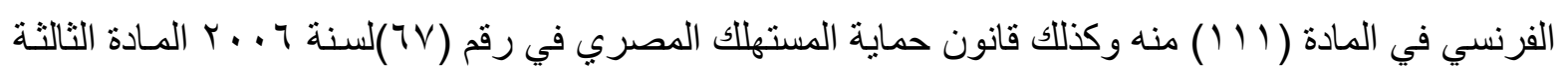
منه وبالمقابل فأن هنالك واجبا بالاستعلام أو التحري و التحقق ملقى على عاتق المستهللك بمعنى أن يسعى الى

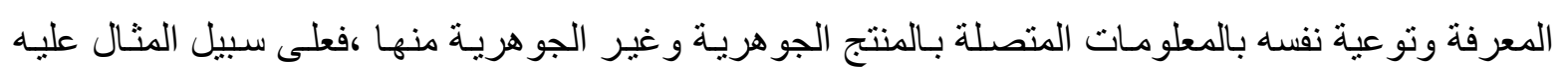

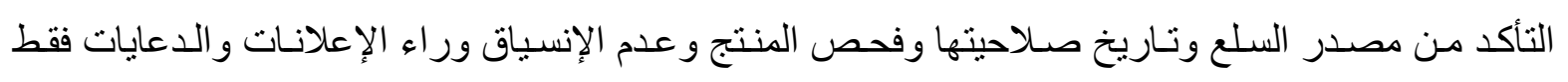
ويعتبر واجب الإستعلام مكملا لإلتزام المهني بالإعلام وذللك لإشاعة روح التعاون بين المتعاقدين(r) . . ل 
يتضح مما تقدم إنّ على الطرف القوي في العقد وهو المنتج أو المجهز حين يعلن عن عرض السلعة ويقدم المستهلك على التعاقد معه فإنه يجب عليه ذكر كافة البيانات وإبداء النصح على وجـه تحقيق علم كافي

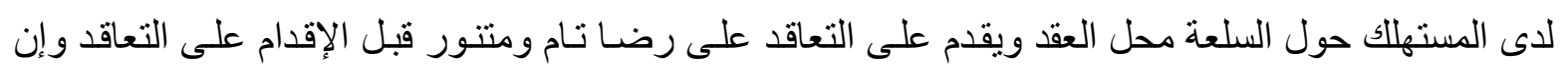

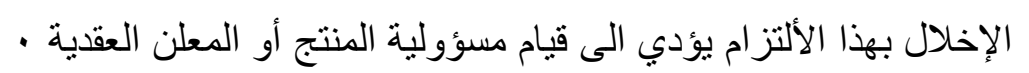

\section{المبحث الثاني- هماية المستهلك أثناء تنفيذ العقد}

تسعى التشريعات الوضعية لحماية المستهلك ليس فقط قبل إبر ام العقد بل حتى أثناء تتفيذه نظر العدم التوازن بين طرفي العلاقة العقدية فالمستهلك هو الطرف الضعيف في العقد، وتتمثل حقوف المستهلك في هذه

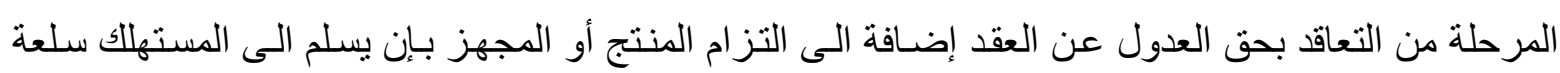

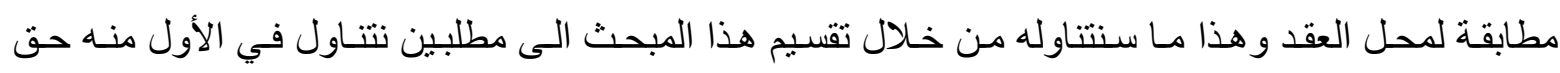
المستهلاك في العدول عن العقد وفي المطلب الثاني الالتزام بضمان المطابقة :

المطلب الأول- حق المستـهلك في العدول عن العقد

نظر الأن المستهلك في عقود التجـارة الإلكترونيـة ليس لديـه الإمكانيـة الفعليـة لمعاينـة المنتج قبل إبرام

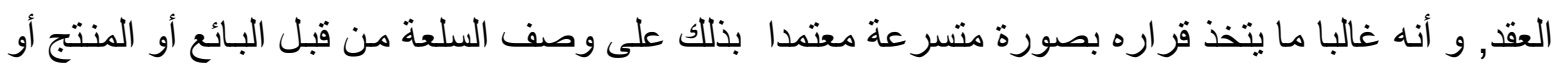

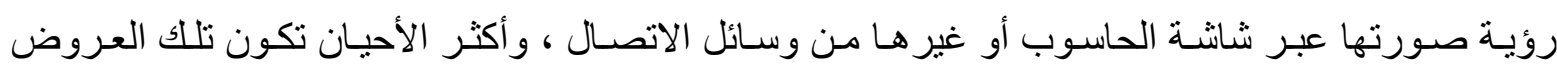
محاطة بوسائل الإغر اء و الدعاية و الإعلان مما يدفع المستهلك الى إبر ام العقد متأثرا بتلك الوسائل ، مما يؤدي التي

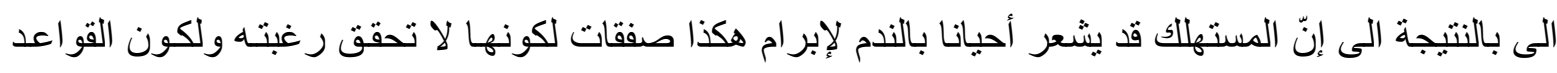
العامة تعجز عن توفير الحماية الكافية للمستهلك ، لذا ذهبت أغلب التشريعات الى إقرار حق المشتري بالعدي العدول

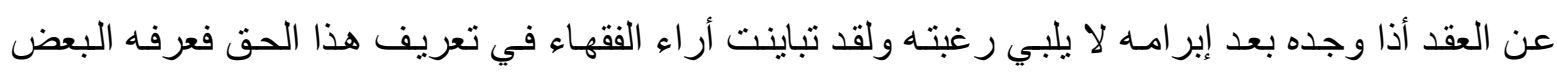

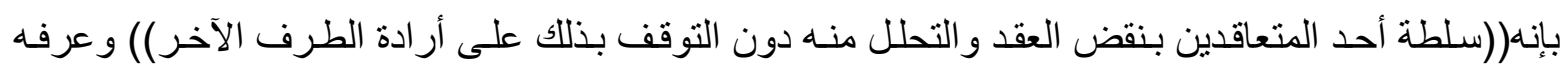
البعض الآخر بأنه (( إعادة المتعاقدين الى الحالة التي كانا عليها قبل إبر ام العقد ويكون ذلك بإن المشتري يرد

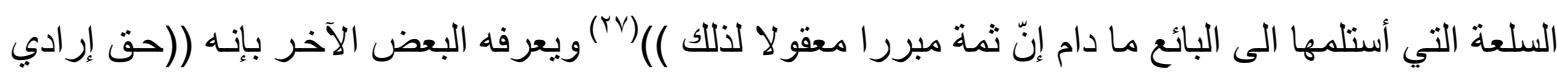

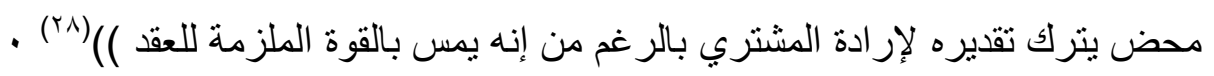

يتبين لنـا ممـا تقدم من التعـاريف السـابقة إنّ حق العدول هو وسيلة يتمكن بها المشتري من العدول و التراجع عن العقد إذا تبين له إن محل العقد لا يتمتع بالمواصفات المعينة عند إبر ام العقد و إن هذا الحق يجد

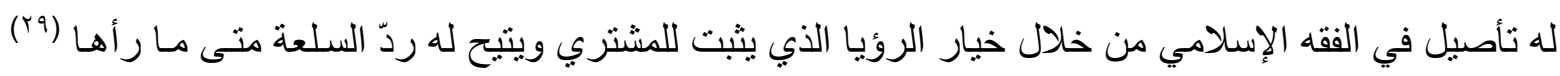

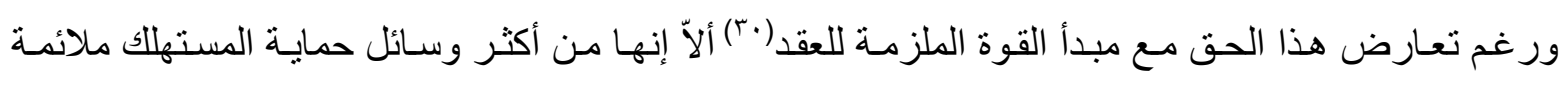
للتجـارة الإلكترونيـة حيث ينعدم التواصل المباثـر بين المنتج و المستهلك وهذا الأخير تسبطر عليه وسـائل و إغر اءات الدعاية والإعلان في المو اقع الإلكترونيـة والتسـهيلات الممنوحة لـه من قبل المنتجين ولذا في هذه

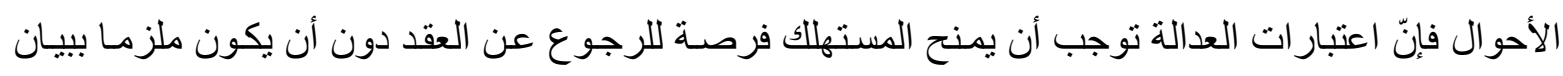

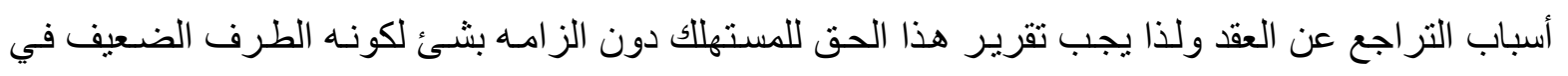


العقد(rاr) •وبصدد موقف التشريعات الوضعية فقد أثشار المشرع الفرنسي الى هذا الحق في القانون رقم (Yr) لسنة (91191) في عمليات البيع عن بعد حيث يحق للمستهلك وبعد تسلم المبيع حق رده و إرجاعها و إسترداد الثمن خـلال سبعة أيسام من تاريخ تسلم المبيع(rr) وكذلك بين قانون حمايـة المستهلك العر اقي رقم ( (1) لسنة

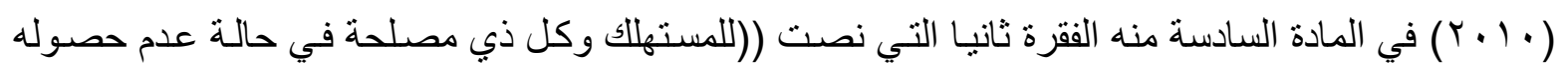
على المعلومات المنصوص عليها في هذه المـادة إعادة السـع كلا أو جزءا الى المجهز . . . ()) وكذللك مـا أشتار إليه قانون حماية المستهلك المصري في المادة الثامنة ،منـه ويذهب رأي في الفقه الـى إنـه في حالـة عدم وجود إتفاق مخالف فإنّ حق العدول لا يمكن ممارسته بالنسبة لتوريد الخدمات التي بدأ تنفيذها بالاتفاق مـع المستهلك و عقود توريد السلع و الخدمات التي يتحدد أثمانها طبقا لتباين أسعار السوق والتي ليس بوسع المنتج و البائع السيطرة عليها و إنّ حق العدول يجب أنّ لا يسمح للمستهلك بالإستفادة من الخدمـة دون أنّ يدفع مقابلها

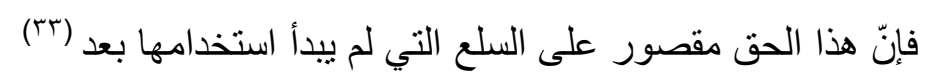

ولكن مما يجب ملاحظته هو إنّ حق المستهلك في العدول يجب أن يمارس خـلال فترة زمنيـة محددة

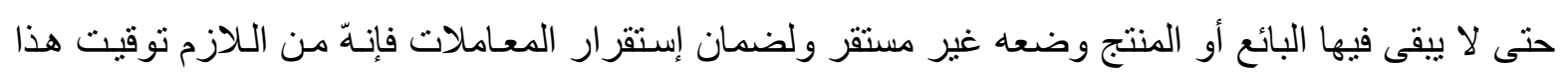

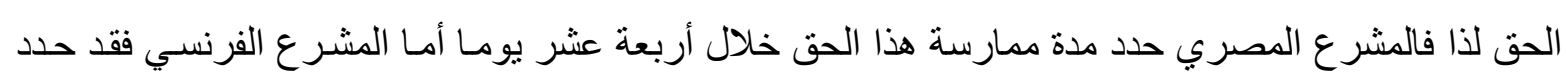

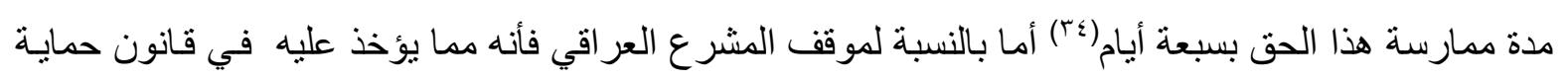

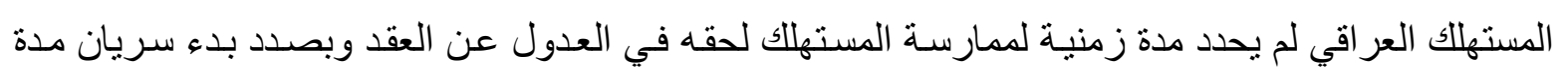
العدول فالبعض يفرق بين الأموال و الخدمات ،فبالنسبة للأمو ال فيبدأ سريان هذه المدة من تاريخ إستلامها من فئن

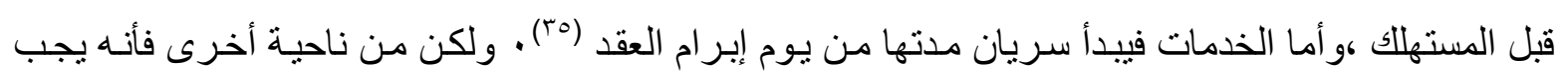

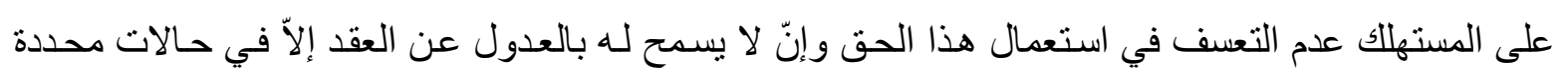
وعلى سبيل الحصر ويجب وضع ضابط أو معيار معين لضمان عدم التعف في استعمال هذا الحق •

ويتبين لنا من خلال ما تقدم إنّ حق العدول عن العقد مقرر لمصلحة المستهلك بسبب طبيعة هذا العقد ويحتل أهمية كبيرة في هذا النوع من البيوع لضمان التوازن بين طرفي العلاقة العقدية لكون المستهلك لا يرى

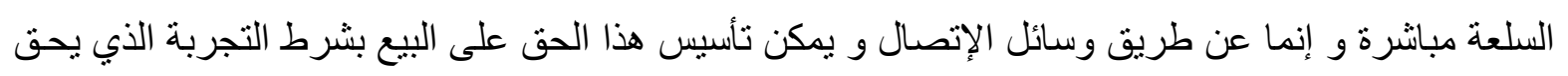

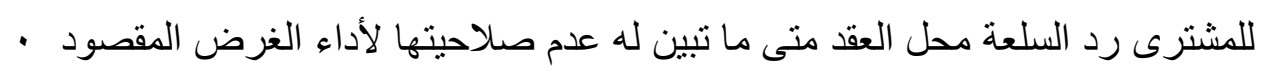

المطلب الثاني- الالتزام بضمان المطابقة

إنّ ظهور وسائل الاتصال الحديثة أدى الى ظهور أنماط تعاقدية جديدة عن طريق الأنترنت أو الهاتف

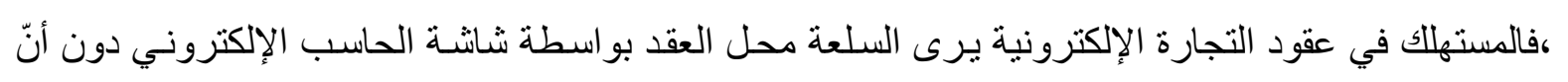

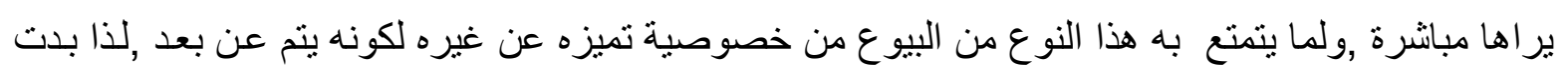

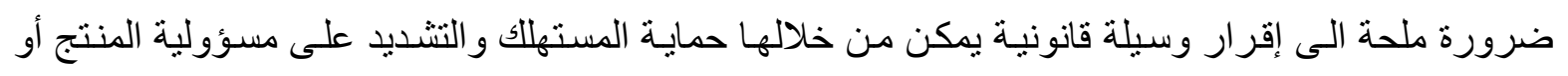

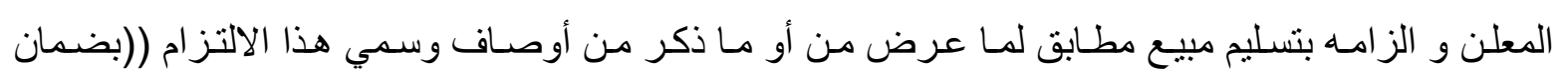


المطابقة )) ولأجل الوقوف على مفهوم دقيق لهذا الالتزام سنقوم بتقسيم هذا المطلب الى فرعين نتنـاول في الأول منهما تعريف الالتزام بضمان المطابقة وفي الثاني منهما مضمون الالتزام بضمان المطابقة :

\section{الفرع الأول- تعريف الالتزام بضمهان الامطابقة}

لم يرد في أغلب التشريعات الوضعية و قو انين حمايـة المستهلك تعريف محدد لهذا الالتز ام إنمـا تمثّ الإشـارة إليه في بعض مواد قانون حمايـة المستهلك والقوانين المدنية ولكن الفقه سـى جاهدا الى التوصل

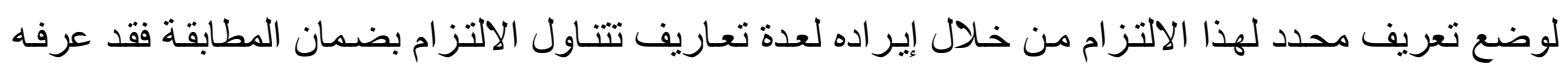

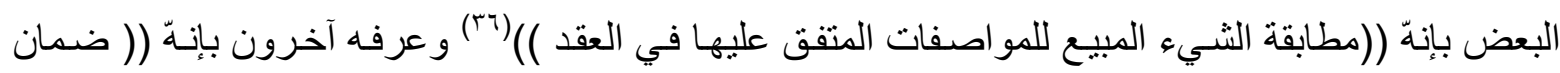

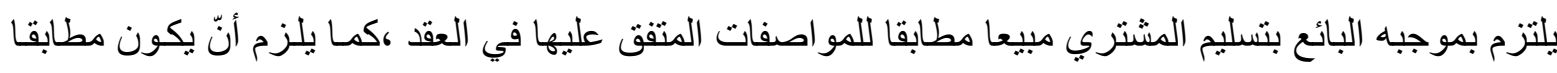

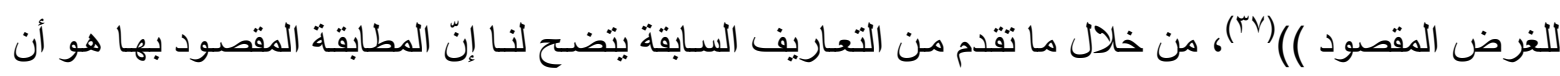
يكون المبيع مطابقا لما ذكر من مواصفات أو عرض في الصور , و المطابقة إمـا أن تكون مطابقة موضو عية الهون

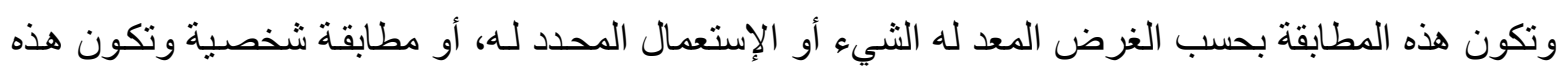

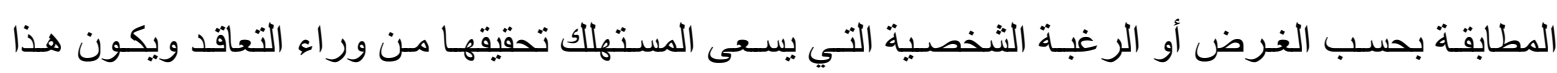
الغرض خاص بالمستهلك و إنّ ضمان المطابقة من الحقوق الأساسية التي يجب أنّ يمتع بها المستهلك • وبصدد بيان الأساس القانوني لضمان المطابقة فيذهب البعض الى إنّ اساسـه يتمثنل في كونـه أحد تطبيقات حسن النية

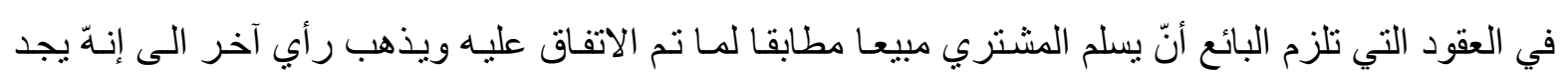

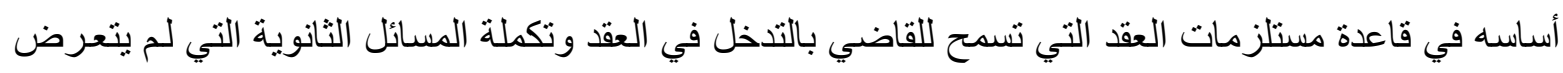

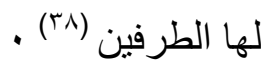

أما على صعيد التشريعات فقد نصت أغلب قوانين الاستهلاك على الزام المنتج بضمان المطابقة ، منها

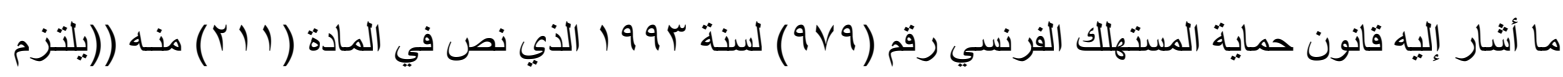
البائع بأن يسلم شيئا مطابقا للعقد ويضمن عيوب المطابقة الموجودة عند التسليم ))وبين قانون حماية المستهلك

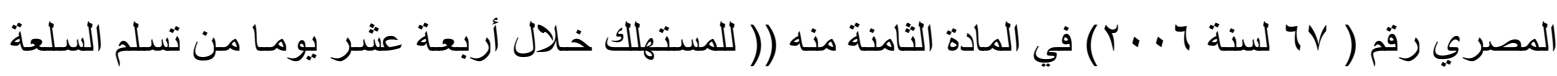
الحق في استبدالها أو أعادتها مع استرداد قيمتها وذلك أذا شاب السلعة عيبا أو كانت غير مطابقة للمو اصفات

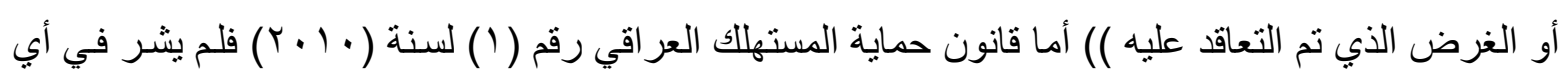
مادة منه الى هذا الضمان ولكن يبدو لنا إنه قد أكتفى في القو اعد العامـة المقررة في القانون المدني ، وكان

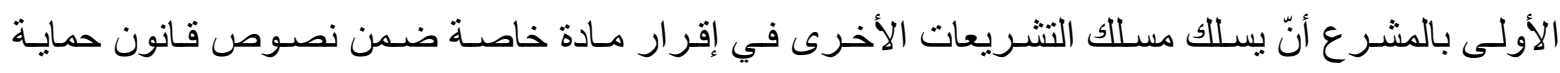
المستهلك العر اقي تلزم المنتج أو البائع بتسليم مبيع مطابق المواصفات المتفق عليها في العقد .

\section{الفرع الثاني- هضمون إلتزام المنتج بضسمان المطابقة}

أثـارت التشـريعات الوضـعية الـى إنـة يجب على المنتج أو البـائع تسـليم مبيعـا مطابقا الـى المستهلك وتختلف المطابقة بحسب اتفاق الطرفين فأما أنّ يكون المبيع مطابقا للغرض أو الاستعمال المعد لـه الثـيء أو أنّ يكون مطابقا لما تم الاتفاق عليه في العقد من مواصفات لذا يختلف مضمون المطابقة من عقد الى آخر و 
بناءا عليه يختلف التزام المنتج بتسليم مبيع مطابق ففي الحالة الأولى يلتزم المنتج بإن يسلم مبيعا مطابقا من الناحيـة الوظيفيـة وصـلاحيته للاستعمال وفقـا لــا اعد لـه من الغرض الذي صنـع من اجله ويتم تحديد هذه المطابقة إما بحسب طبيعة المنتج أو من خلال الغرض المعد له، والاستعمال المقصود به هو الاستعمال العادي

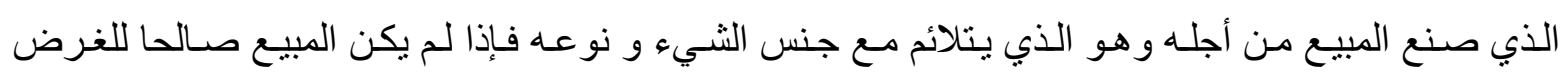
المقصود منه كان غير مطابق و عندها تقوم مسؤولية المنتج أو البائع في الضمان.

ويجد التز ام المطابقة بهذا المعنى أساسـه في أن عدم المطابقة في هذه الحسالات يؤدي الى حرمـان

المستهلك من الفائدة التي كان يتوقعها عند أبر ام العقد فالمعيار الذي على أساسـه يتحدد الاستعمال هو معيار موضوعي يتم تحديده على أسس معينـة ولا تتوقف عند رغبـة المشتري • أمـا الحالـة الأخرى فهي المطابقة الوصفية حيث نلاحظ في كثير من الأحيان إنّ المستهلك عند أقدامه على التعاقد وشر اء سلعة معينة يشترط عند أبر ام العقد توفر مو اصفات معينة في الثيء محل العقد يلبي رغباته الثخصية تأكيدا منه على أهميتها لـه حيث

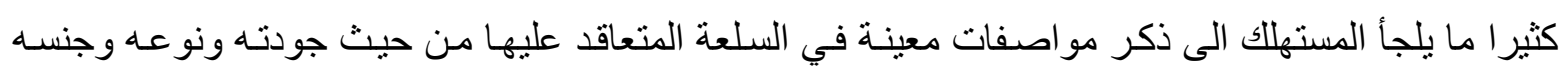
فيو افق الطرف الآخر في العقد ويضمن توفر هذه المواصفات و عندها يلتزم المنتج بتسليم مبيع مطابق لهـا ذكر من مواصفات تم الاتفاق عليها في الثـيء محل العقد فالمعيار المتبع في تحديد مدى مطابقة المبيع لرغبات المشتري هو معيار شخصي يعتمد على رغبة المستهلك نفسه وبالتالي فإنه يجب على المنتج أو البائع أنّ يسلم

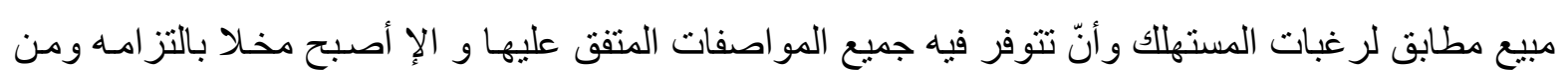

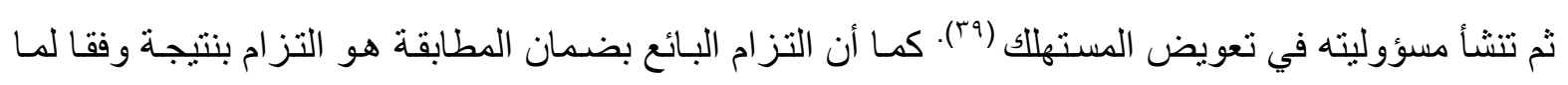

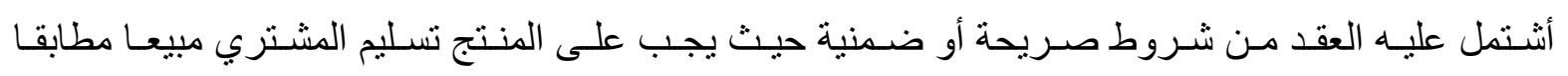
للمواصفات المذكورة في العقدو الا كان مسؤو لا عن تعويض الضرر الذي يصيب المستهلك بسبب عدم المطابقة (•؛) كما إنّ مطابقة المبيع للغرض الخـاص بالمشتري من الأمور التي يصعب بيانها لكونها مسـألة

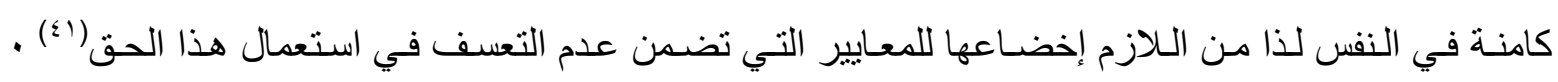

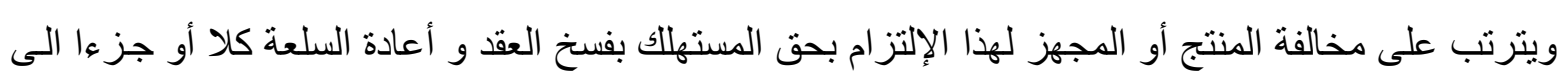
المنتج مع المطالبة بالتعويض عن جميع الأضر ار التي أصابته جراء ذللك.

يتضـح مـن خـلال مـا تقدم إنـه يوجد معيـارين ينتم على أساسـهما تحديد مدى التز ام المنتج بالضـمان

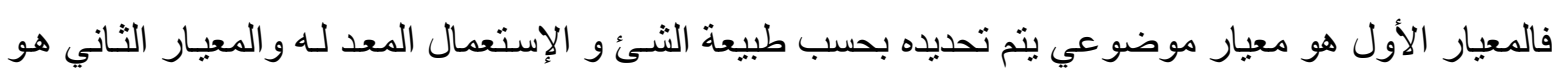
معيار شخصي يتم تحديده بحسب رغبة المشتري ومدى ملائمة الثيء محل العقد لتحقيق رغباته الخاصة .

من خلال در استنا لهذا البحث توصلنا الى جملة من النتائج والتوصيات سنبينها من خلال تقسيم خاتمـة

الخاتمة هذا البحث الى النتائج و التوصيات : 


$$
\text { أولا - النتائج }
$$

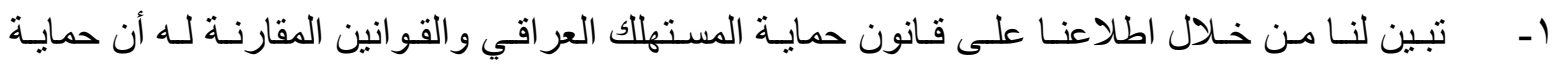
المستهلك في عقود التجـارة الإلكترونيـة تتوزع على مـرحلتين فأمـا أن تكون قبـل إبر ام العقد و عند تعبيـر المستهلك عن إرادته وتكون أيضا بعد إبرام العقد وعند تتفيذه •

r- أقرت معظم التشريعات الى منح مهله للمستهلك قبل إبرام العقد حتى يتمكن من التفكير و التروي جيدا و إستشـارة ذوي الخبرة و الإختصـاص قبـل إقدامسه على التعاقد مـن أجـل ضـمان رضـا حر وسليم ومتنـور

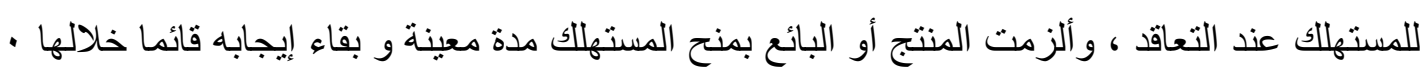
r- يجوز للمستهلك العدول عن العقد بعد إبر امه إذا تبين له إنّ السلعة محل العقد لا تلبي رغباتهـ الثخصية

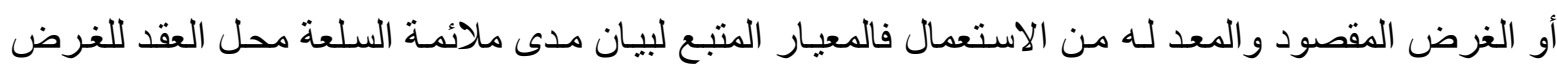

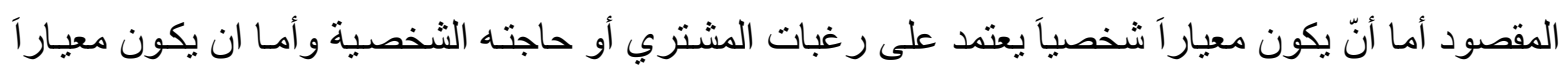

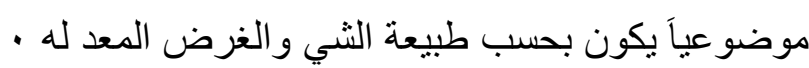
ع - لم يين المشرع العر اقي المدة التي يجب أنّ يمارس خلالها المستهلك حق العدول عن العقد وهذا خلاف

$$
\begin{aligned}
& \text { التشريعات المقارنة التهن } \\
& \text { ثانيا- التوصيات : }
\end{aligned}
$$

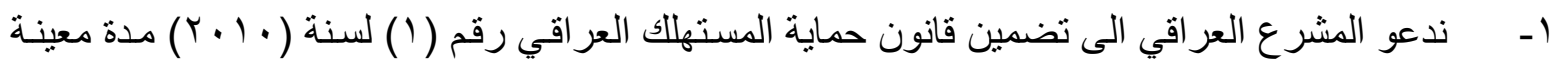
يجب أن يمارس المستهلك فيها حقه في العدول عن العقد أسوة ببقية القوانين المقارنـة حتى لا يبقى الطرف

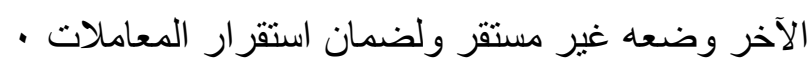

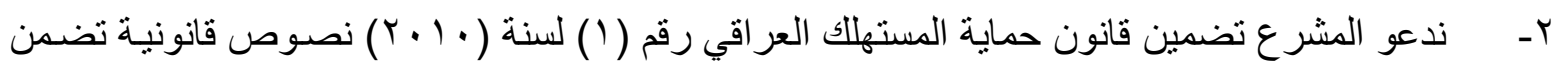
عدم التعسف من قبل المستهلك في إستعمال حقوقه . r- - العمل على إعداد برنامج توعوي شامل من خلال عقد الندوات و المؤتثر ات وبمشـاركة وسـائل الإعلام

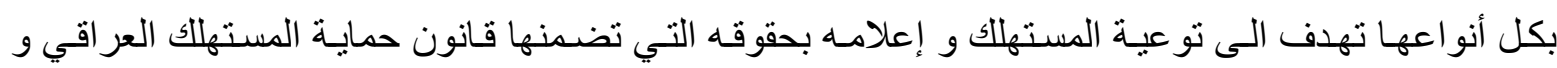
إعلامه بكل منافع ومضار السلع الإستهلاكية من أجل رفع قدرة المستهلك وجعله على درايـة ومعرفة بحقوقه اعله من أجل إقامة التوازن بين طرفي العلاقة العقدية .

إموامئ

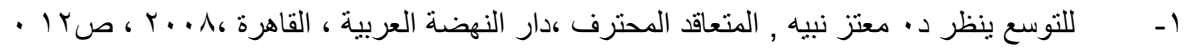

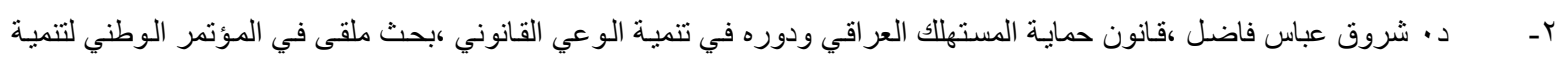

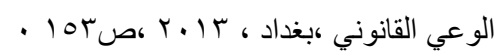

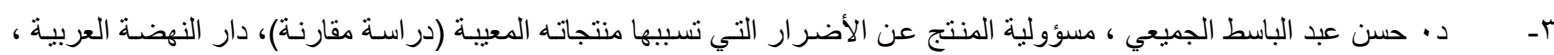

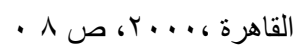

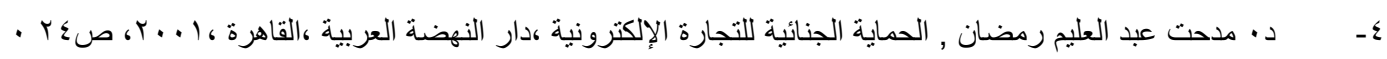

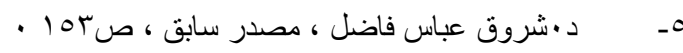

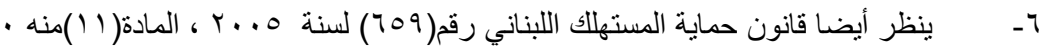




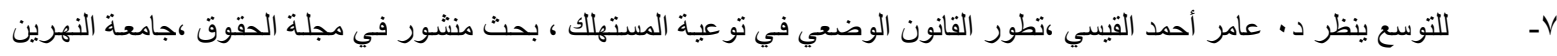

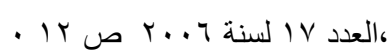

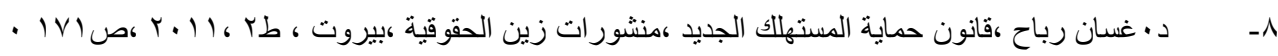

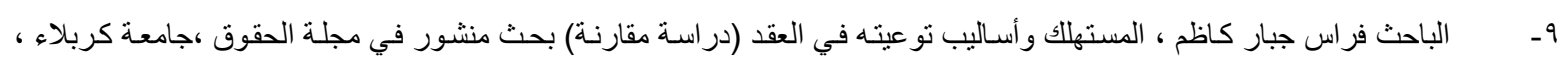

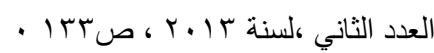

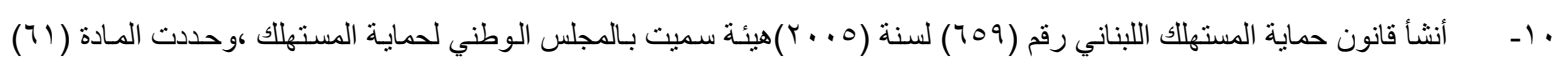

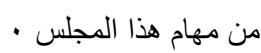
11

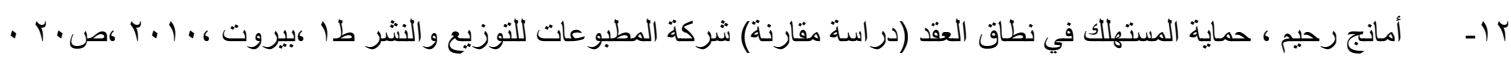

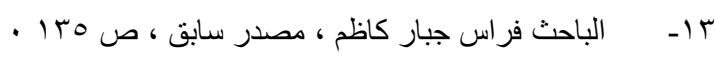

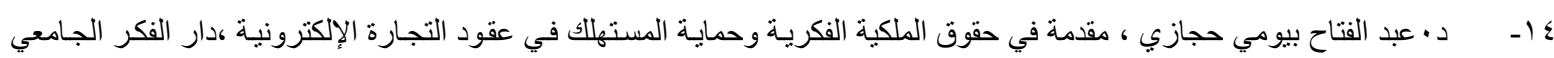

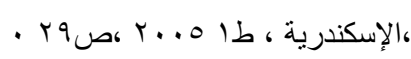

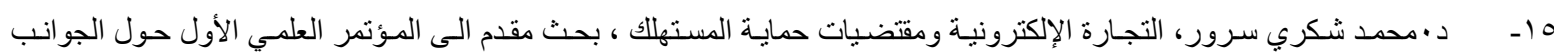

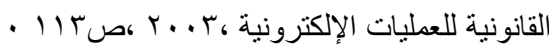

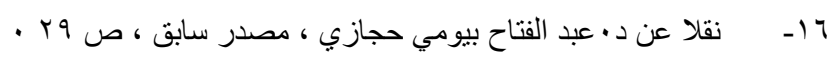

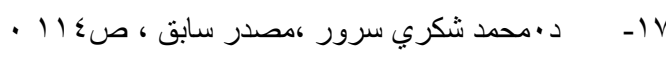

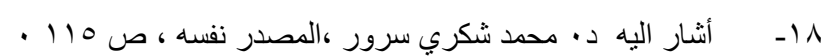

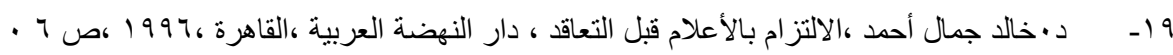

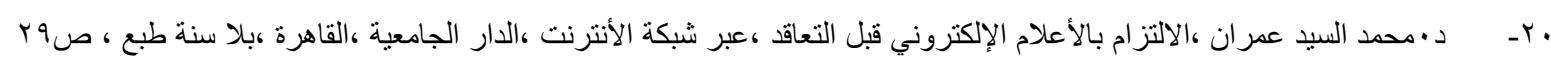

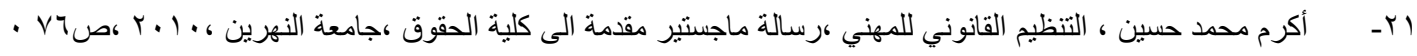

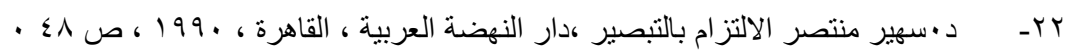

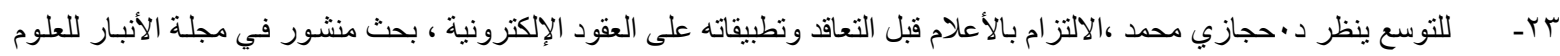

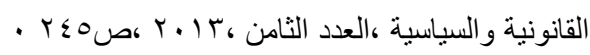

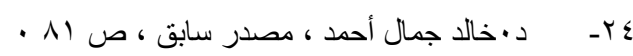

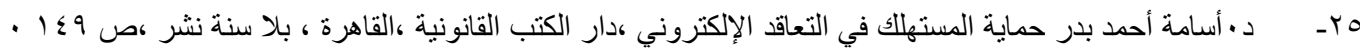
צr

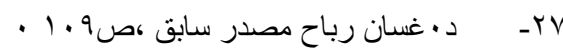

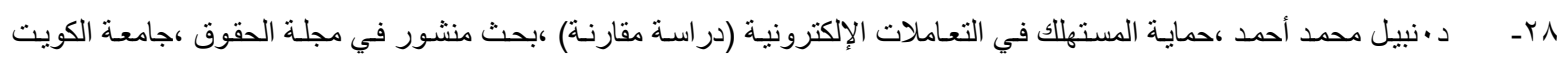

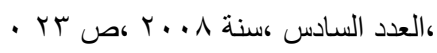
q ب- زيد عماد محسن الموسوي ،الحماية المدنية للمشتري في عقد البيع الإلكتروني ،رسالة ماجستير مقدمة الى مجلس كلية القانون جامعة

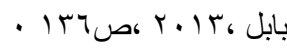

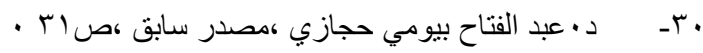

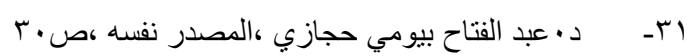

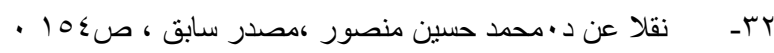

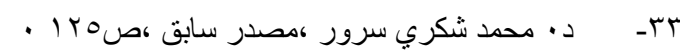

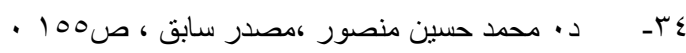

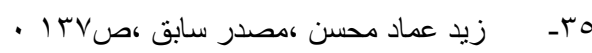

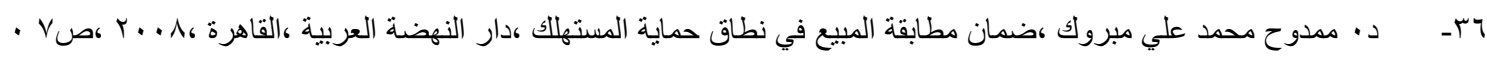

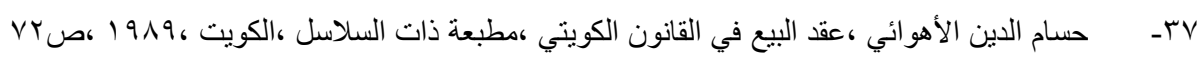

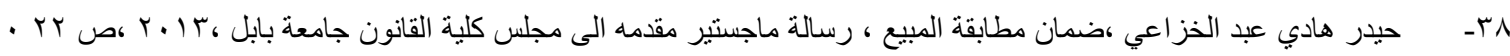

\section{$-\varepsilon \leqslant 0$ ـ}




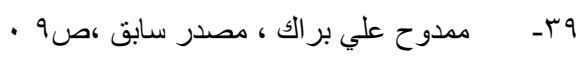

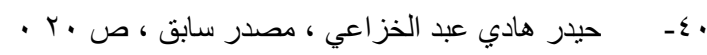

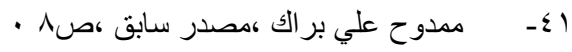

أو لا : المصادر باللغة العربية

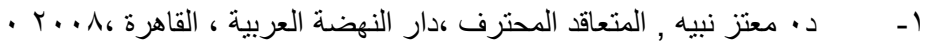

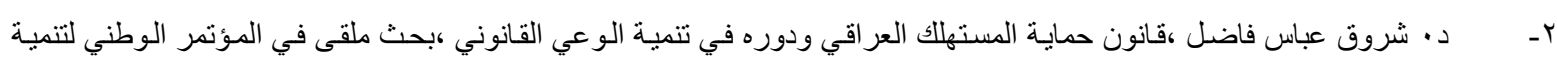

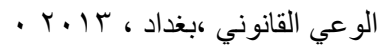

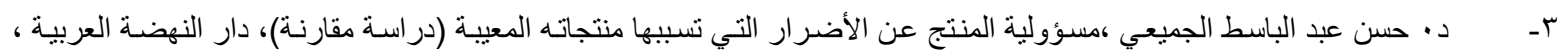
القاهرة ، ... ب .

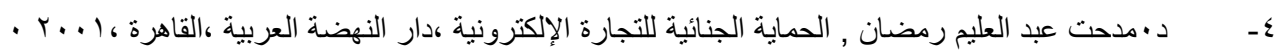

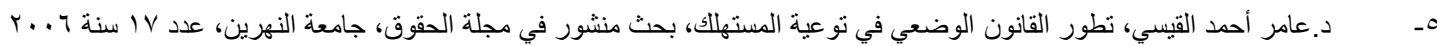

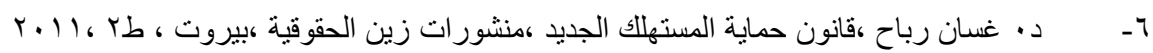

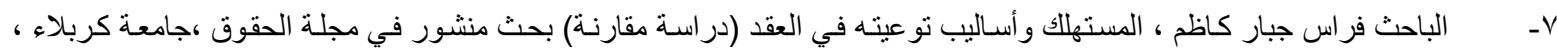

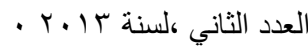

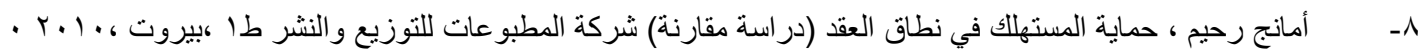

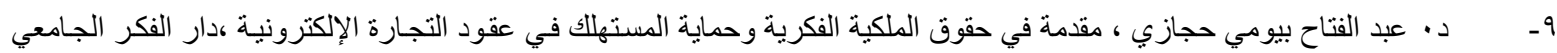

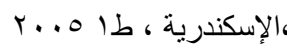

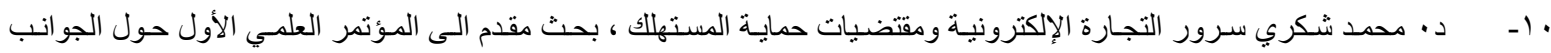

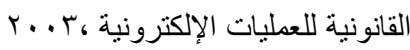

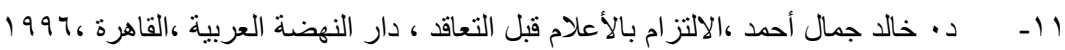

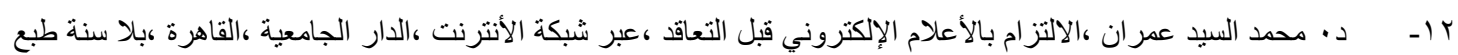

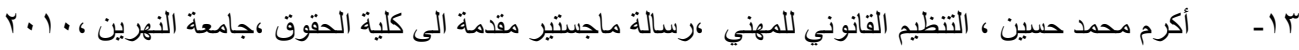

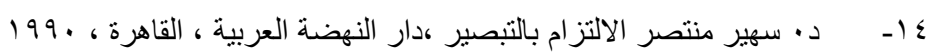

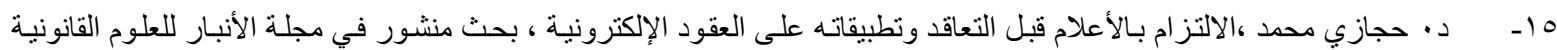

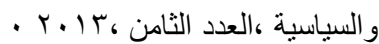

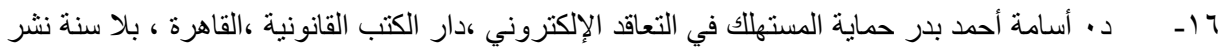

Vا - د • نبيل محمد أحمد ،حمايـة المستهلك في التعاملات الإلكترونية (دراسـة مقارنة) ،بحث منشور في مجلة الحقوق ،جامعة الكويت

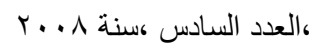

ر ا- زيد عماد محسن الموسوي ،الحماية المدنية للمشتري في عقد البيع الإلكتروني ،رسالة ماجستير مقدمة الى مجلس كلية القانون جامعة

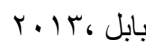

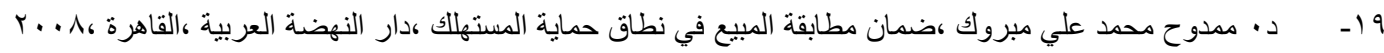

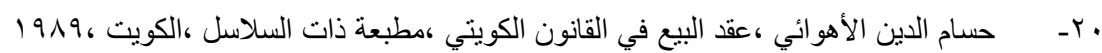

ثانيا - القو انين العربية والأجنبية

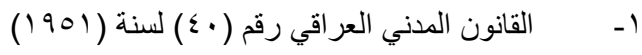

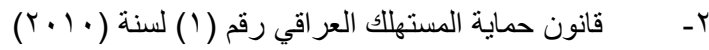

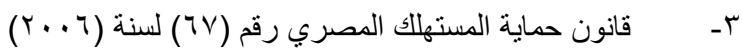

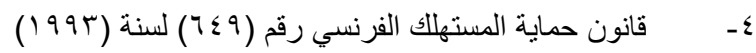

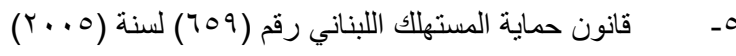

